\title{
QUALIDADE DE SEMENTES E MUDAS DE Schizolobium parahyba PROCEDENTES DO RIO GRANDE DO SUL, SANTA CATARINA E PARANÁ ${ }^{1}$
}

\author{
Edicléia Aparecida Iensen Cherobini², Marília Lazarotto ${ }^{3}$, Marlove Fátima Brião Muniz ${ }^{4}$, Leonita Beatriz Girardi ${ }^{5}$, \\ Diogo Belmonte Lippert ${ }^{6}$, Caciara Gonzatto Maciel $^{6}$
}

(recebido: 14 de maio de 2009; aceito: 30 de junho de 2010)

\begin{abstract}
RESUMO: Neste trabalho, objetivou-se estudar o vigor por diferentes testes e a sanidade de sementes de guapuruvu (Schizolobium parahyba) procedentes dos estados do Rio Grande do Sul (RS), Santa Catarina (SC) e Paraná (PR) e avaliar a qualidade das mudas produzidas por estas sementes. As avaliações em sementes foram: teor de água, germinação, diferentes testes de vigor e sanidade e as de mudas em viveiro foram: sementes duras e mortas, emergência, altura de plântula e comprimento de raiz, diâmetro do colo, peso fresco e peso seco. Para as sementes, as amostras procedentes de SC e PR tiveram melhor desempenho nas avaliações de primeira contagem de germinação, massa seca e envelhecimento acelerado, as quais foram eficientes para estratificar as procedências de sementes em diferentes níveis de vigor. Os fungos encontrados nas sementes foram Aspergillus sp., Alternaria sp., Penicillium sp. e Trichoderma sp. Com relação às mudas, as sementes de PR apresentaram os melhores resultados nos testes em que as diferenças foram significativas (emergência, comprimento de raiz e peso de matéria seca de plântulas). Algumas variáveis de laboratório tiveram correlação com as de viveiro, indicando estreita relação entre os testes.
\end{abstract}

Palavras-chave: Germinação, viabilidade, emergência, plântulas.

\section{QUALITY OF Schizolobium parahyba SEEDS AND SEEDLINGS FROM RIO GRANDE DO SUL, SANTA CATARINA AND PARANÁ STATES}

\begin{abstract}
This research aimed to study the vigor and the quality of Schizolobium parahyba seeds from samples of three different states, Rio Grande do Sul (RS), Santa Catarina (SC) and Paraná (PR) and to evaluate the seedlings quality produced by these seeds. The seeds were submitted to evaluations of moisture content, germination, vigor and healthy. The seedlings quality was evaluated by hard seeds, dead seeds, emergence, seedling height, root length, collar diameter, fresh and dry weight of seedlings. On the seeds evaluations, the samples from SC and PR presented better results for first count of germination, dry matter and accelerate aging. The fungi associated to the seeds were Aspergillus sp., Alternaria sp., Penicillium sp. and Trichoderma sp. About the seedlings evaluations, seeds from PR showed the bests results when the differences between tests were significant (emergence, root length and dry weight of seedlings). Some of the labs variables had correlation with the seedlings variables.
\end{abstract}

Key words: Germination, viability, emergence, seedlings.

\section{INTRODUÇÃo}

A flora brasileira possui uma ampla diversidade, apresentando grande potencial de utilização, entretanto, pouca atenção tem sido dada às espécies nativas, principalmente quanto à sua perpetuação. Uma das exuberantes espécies nativas arbóreas brasileiras é o guapuruvu - Schizolobium parahyba (Vell.) S.F. Blake, pertencente à família Caesalpiniaceae, árvore de grande porte, podendo alcançar $30 \mathrm{~m}$ de altura, que, na primavera, cobre-se de flores amarelas. A espécie é pioneira e seu plantio é indicado para recuperação de áreas degradadas graças ao seu rápido crescimento (LORENZI, 2002).

${ }^{1}$ Parte da dissertação de mestrado do primeiro autor apresentada ao Programa de Pós-Graduação em Engenharia Florestal, Universidade Federal de Santa Maria (UFSM)

${ }^{2}$ Engenheira Florestal, Mestre em Engenharia Florestal - Departamento de Defesa Fitossanitária/DFS - Universidade Federal de Santa Maria/UFSM - 97105-970 - Santa Maria, RS - edicherobini@yahoo.com.br

${ }^{3}$ Engenheira Florestal, Mestre em Engenharia Florestal, Doutoranda em Engenharia Florestal - Departamento de Defesa Fitossanitária/DFS Universidade Federal de Santa Maria/UFSM - 97105-970 - Santa Maria, RS - lilalazarotto@ yahoo.com.br

${ }^{4}$ Engenheira Agrônoma, Professora Dra. em Fitotecnia - Departamento de Defesa Fitossanitária/DFS - Universidade Federal de Santa Maria/UFSM - marlovemuniz@yahoo.com.br

${ }^{5}$ Engenheira Agrônoma, Mestranda em Engenharia Agrícola - Departamento de Defesa Fitossanitária/DFS - Universidade Federal de Santa Maria/UFSM - 97105-970 - Santa Maria, RS - lbgirardi@ hotmail.com

${ }^{6}$ Engenheiro(a) Florestal, Mestrando(a) em Engenharia Florestal - Departamento de Defesa Fitossanitária/DFS - Universidade Federal de Santa Maria/UFSM - diogo_b_lippert@hotmail.com, caciaragonzatto@gmail.com

Cerne, Lavras, v. 16, n. 3, p. 407-413, jul./set. 2010 
O conhecimento dos processos básicos de reprodução das espécies nativas é um dos primeiros passos a serem dados para garantir sua preservação. Existe uma grande preocupação por parte dos pesquisadores e analistas de sementes, sobretudo os que trabalham com espécies florestais, em conduzir estudos que forneçam informações sobre a qualidade das sementes, especialmente no que diz respeito à padronização, agilização, aperfeiçoamento e estabelecimento dos métodos de análise (MACHADO et al., 2002).

Segundo Marcos Filho (1994), o vigor das sementes é consequência de um conjunto de características ou propriedades que determinam o seu potencial fisiológico, ou seja, a capacidade de apresentar desempenho adequado quando expostas a diferentes condições ambientais. Existem os testes de vigor que se baseiam no desempenho de plântulas, tanto os realizados em condições de laboratório, sob condições controladas, quanto aqueles realizados em condições de campo (NAKAGAWA, 1999). Esses últimos fornecem ideias mais precisas sobre a real qualidade das mudas que serão produzidas, pois estão sujeitos a variações do ambiente.

Além do escasso desenvolvimento de pesquisas com relação à qualidade fisiológica de sementes florestais nativas, a qualidade sanitária dessas sementes é ainda menos estudada. De modo geral, vários danos podem ser provocados por patógenos, associados às sementes. Dentre eles, morte em pré-emergência, podridão radicular, tombamento de mudas, manchas necróticas em folhas, caules, deformações como hipertrofias e subdesenvolvimento, descoloração de tecidos e infecções latentes (NEERGAARD, 1979), além da semente servir como veículo de disseminação de organismos patogênicos em áreas ainda isentas de doenças.

Para Ferreira (1989), a contaminação das sementes e frutos de essências florestais ocorre predominantemente no solo onde são colonizados por fungos saprófitas e parasitas facultativos que têm vida saprofítica no solo ou na matéria orgânica, tais como: Alternaria sp., Cylindrocladium sp., Fusarium sp., Phoma sp., Phomopsis sp., Pythium sp., Rhizoctonia sp. e Trichoderma sp. Durante o beneficiamento ou armazenamento, os fungos são disseminados para as sementes sadias.

Diante do exposto, nesta pesquisa, objetivou-se estudar o vigor através de diferentes testes; a sanidade de sementes de guapuruvu procedentes dos estados Rio Grande do Sul, Santa Catarina e Paraná; avaliar a qualidade das mudas produzidas por estas sementes; bem como correlacionar variáveis obtidas em laboratório e a campo.

\section{MATERIAL E MÉTODOS}

Foram utilizadas sementes de guapuruvu (Schizolobium parahyba) procedentes de três estados (e municípios) do Brasil: Rio Grande do Sul (Santa Cruz do Sul); Santa Catarina (Rio do Sul) e Paraná (Irati). Antes da execução dos testes descritos a seguir, exceto para o teste de sanidade, foi realizada a superação de dormência, por meio de escarificação mecânica no lado oposto do embrião (SOUZA CRUZ, 2001).

\subsection{Avaliação das sementes}

Os testes descritos a seguir foram realizados no Laboratório de Fitopatologia do Departamento de Defesa Fitossanitária da UFSM.

$\mathrm{O}$ teor de água das sementes foi determinado pelo método da estufa (BRASIL, 1992), com quatro subamostras de 10 sementes, sob temperatura de $105^{\circ} \mathrm{C} \pm 3^{\circ} \mathrm{C}$ por 24 horas e os resultados foram expressos em percentagem. Os testes descritos a seguir foram realizados para cada uma das três procedências. a) Primeira contagem de germinação e teste de germinação: dez repetições de dez sementes foram colocadas em caixas plásticas do tipo gerbox, forradas com três folhas de papel-filtro umedecidas com água destilada na proporção de duas vezes o peso do papel seco. A incubação foi a $25^{\circ} \mathrm{C}$ com fotoperíodo de 8 horas sob luz branca. A primeira contagem de germinação, somente de plântulas normais, foi realizada aos 14 dias e a germinação, considerando-se plântulas normais, anormais, sementes duras e mortas, avaliada aos 21 dias; b) Índice de velocidade de germinação (IVG): conduzido de acordo com Popinigis (1985), em conjunto com o teste de germinação, com contagens diárias do número de plântulas por repetição, somando-se o número de sementes germinadas por dia, dividas pelo respectivo número de dias transcorridos desde a semeadura; c) Comprimento de plântulas: somente as plântulas normais da primeira contagem e da germinação foram medidas com auxílio de régua milimetrada. Os resultados foram expressos em centímetros; d) Massa fresca e massa seca de plântulas: para a massa fresca, fez-se pesagem das plântulas normais com balança analítica de 0,001 g de precisão. Para a realização da massa seca, as plântulas da massa fresca foram colocadas em sacos de papel divididas em quatro repetições e acondicionadas em estufa a $80^{\circ} \mathrm{C}$ por 24 horas, após, estas foram pesadas fez-se média por repetição para ambas as variáveis. Os resultados foram expressos em mg/plântula; e) Envelhecimento acelerado: foi utilizado o 
método da câmara de envelhecimento (KRZYZANOWSKI et al., 1999). A temperatura foi de $42^{\circ} \mathrm{C} \pm 2^{\circ} \mathrm{C}$, com dez repetições de dez sementes. Decorrido o período de 48 horas, estas foram colocadas para germinar sob as mesmas condições do teste de germinação. A avaliação foi realizada aos 21 dias; f) Teste de sanidade: realizado pelo método "blotter test", com 200 sementes divididas em quatro repetições de 50, colocadas em caixas plásticas tipo "gerbox" forradas com três folhas de papel-filtro esterilizadas e umedecidas com água destilada esterilizada. A incubação foi a $25^{\circ} \mathrm{C}$ com fotoperíodo de 12 horas, sob luz branca, durante sete dias, quando avaliaram-se as alterações presentes no tegumento pela presença ou não de fungos, com auxílio de microscópio estereoscópico e óptico.

\subsection{Avaliação de mudas}

O experimento foi realizado em casa de vegetação climatizada. A avaliação das mudas partiu da semeadura em tubetes, com substrato comercial para espécies florestais Plant Max, utilizando-se 100 sementes, divididas em quatro repetições de 25 . A superação de dormência foi realizada de acordo com o descrito anteriormente (item 2.1). Foram realizadas as seguintes avaliações: a) Sementes duras e mortas: nos tubetes que não apresentaram emergência, com os resultados expressos em percentagem; b) Emergência: realizou-se a contagem de plântulas emergidas por procedência, 30 dias após a semeadura. Os resultados foram expressos em percentagem; c) Altura média das mudas e comprimento de raiz: medidos com auxílio de régua milimetrada, com os valores expressos em centímetros; d) Diâmetro do colo: usando-se um paquímetro digital, com os valores expressos em centímetros; e) Peso fresco e peso seco de mudas: os mesmos procedimentos descritos anteriormente para massa seca e massa fresca de mudas foram realizados. Todas as avaliações de mudas foram realizadas aos 45 dias após a semeadura, exceto a emergência.

\subsection{Análise estatística}

O delineamento experimental utilizado foi o completamente casualizado, variando o número de repetições de acordo com o teste. Os dados em percentagem foram transformados em $\operatorname{arc} \operatorname{sen} \sqrt{x / 100} \mathrm{e}$ submetidos à análise de variância. A comparação de médias entre as diferentes procedências foi realizada por meio do teste de Tukey a 5\% de significância. Também foi realizada correlação linear simples entre as variáveis germinação e emergência de plântulas em viveiro as sementes mortas no viveiro, peso fresco de mudas, índice de velocidade de germinação, comprimento de plântulas, massa seca de plântulas e envelhecimento acelerado. $\mathrm{O}$ pacote estatístico utilizado foi o SANEST (ZONTA \& MACHADO, 1986).

\section{RESULTADOS E DISCUSSÃO}

As amostras procedentes do Rio Grande do Sul (RS), Santa Catarina (SC) e Paraná (PR) estavam com teores de água de 8,2,6,3 e 7,1\%, respectivamente. Estes valores são considerados satisfatórios, pois teores de água abaixo de $13 \%$ não comprometem a qualidade das sementes, permitindo seu armazenamento por maiores períodos (MEDEIROS, 2001).

Na Tabela 1, encontram-se os valores, em percentagem, referentes ao teste de germinação. As sementes de guapuruvu, independentemente da procedência, apresentaram baixa germinação.

Tabela 1 - Valores médios (\%) de germinação (G), sementes duras (SD) e sementes mortas (SM) de Schizolobium parahyba procedentes dos estados do Rio Grande do Sul, Santa Catarina e Paraná.

Table 1 - Average values (\%) of germination (G), hard seeds (SD) and dead seeds (SM) of Schizolobium parahyba from Rio Grande do Sul, Santa Catarina and Paraná states States.

\begin{tabular}{lccc}
\hline Locais & G & SD & SM \\
\hline RS & $26 \mathrm{~b}^{*}$ & $40 \mathrm{a}$ & $34 \mathrm{a}$ \\
SC & $34 \mathrm{a}$ & $49 \mathrm{a}$ & $17 \mathrm{~b}$ \\
PR & $35 \mathrm{a}$ & $40 \mathrm{a}$ & $25 \mathrm{~b}$ \\
\hline CV $(\%)$ & 1,9 & 3,7 & 5,3 \\
D.M.S & 0,32 & 0,48 & 0,66 \\
\hline
\end{tabular}

* Médias seguidas pela mesma letra, na coluna, não diferem entre si pelo teste de Tukey em nível de 5\% de significância. 
A escarificação mecânica em sementes de guapuruvu não se mostrou eficiente para as amostras utilizadas no presente estudo, ao contrário da observação de Souza Cruz (2001) que testou diversos métodos de superação de dormência para esta espécie e verificou que a escarificação mecânica facilitou a penetração de água, já que o tegumento impossibilitava a embebição, etapa necessária à germinação. A alta percentagem de sementes mortas, especialmente na procedência de $\mathrm{RS}$, pode indicar problemas nas condições de armazenamento de sementes, favorecendo sua deterioração e crescimento de fungos apodrecedores de sementes. Fazendo uma análise do teste, os melhores resultados foram verificados para as procedências SC e PR, já que apresentaram maior germinação e menor percentagem de sementes mortas.

Os resultados dos testes de vigor realizados em guapuruvu estão apresentados na Tabela 2. Observase que, apesar dos valores baixos, as sementes procedentes de SC apresentaram maior percentagem de plântulas normais na primeira contagem de germinação, seguida de PR, o que reflete um maior vigor dessas sementes em relação à procedência RS. Para Nakagawa (1999), o teste de primeira contagem baseia-se no princípio de que, amostras com maiores percentagens de plântulas normais, na primeira contagem, são as mais vigorosas.

Com relação ao Índice de Velocidade de Germinação (IVG) e ao comprimento de plântulas (CP), não houve diferenças significativas entre as três procedências.

$\mathrm{Na}$ avaliação da variável massa fresca de plântulas, as sementes procedentes do RS apresentaram os maiores valores, resultado este que foi inverso a todos os outros testes. Já para massa seca, SC e PR foram as melhores procedências, como já havia sido observado nos outros testes onde as diferenças significativas haviam ocorrido.

Em relação aos resultados do teste de envelhecimento acelerado, ainda na Tabela 2, o qual testa a capacidade das sementes de permanecerem viáveis após períodos sob condições adversas, verificaram-se diferenças significativas entre as procedências. As sementes de procedência PR foram as mais vigorosas, com maior percentagem de germinação após o envelhecimento, seguidas de SC a qual não diferiu nem de PR e nem de RS, esta última com germinação mais baixa.

Cerne, Lavras, v. 16, n. 3, p. 407-413, jul./set. 2010
Silva et al. (1998), estudando sementes de Cucumis anguria observaram que o período de 48 horas de envelhecimento acelerado possibilitou a identificação dos lotes com diferentes níveis de vigor. Perez et al. (1999), estudando efeito de envelhecimento acelerado em sementes de canafístula (Peltophorum dubium), verificaram que condições de alta temperatura e umidade podem ajudar na superação de dormência, quando o período de exposição for de até 48 horas.

Com os resultados expostos na Tabela 2, verificouse que as avaliações de primeira contagem de germinação, massa seca e envelhecimento acelerado foram eficientes para estratificar os lotes de sementes de guapuruvu em diferentes níveis de vigor, sendo as de SC e PR as com maior vigor e RS a de menor vigor relativo aos testes realizados. Os fungos associados às sementes de guapuruvu foram: Trichoderma sp., fungo de maior incidência (44,8\% em SC e 14,8\% em RS), não sendo observado em PR; Alternaria sp. ocorreu em todas as amostras, com incidências de 3, 3 e 10,9\% para RS, SC e $\mathrm{PR}$, respectivamente. Já Penicillium sp. e Aspergillus sp. só ocorreram nas amostras do RS e PR, sem diferença significativa e com incidência máxima de Aspergillus spp. de $5 \%$ em RS.

Scalon et al. (2007) detectaram fungos do gênero Rhizopus e Penicillium em sementes de faveiro Dimorphandra mollis Benth., mesmo após o tratamento das sementes com hipoclorito de sódio. A presença de Aspergillus spp. e Penicillium spp. em sementes é muito comum, indicando que podem ter ocorrido problemas no armazenamento das mesmas. Segundo Cherobini et al. (2008), os gêneros Penicillium e Aspergillus têm a capacidade de reduzir o poder germinativo da semente e causar a morte do embrião. O mesmo autor encontrou correlações negativas entre a incidência desses dois gêneros fúngicos e a percentagem de germinação de sementes de cedro (Cedrela fissilis).

$\mathrm{Na}$ Tabela 3, encontram-se os resultados referentes às avaliações realizadas em mudas oriundas de sementes de guapuruvu de diferentes procedências. Verifica-se que as sementes coletadas no PR apresentaram maior emergência de plântulas e menor percentagem de sementes duras e mortas. Nas outras variáveis, também pode-se observar diferenças significativas entre as três procedências, como no comprimento da raiz, com SC e PR superiores, e no peso fresco, onde PR foi, novamente, a procedência de valor superior. 
Tabela 2 - Valores médios de primeira Contagem de germinação (PCG), Índice de Velocidade de Germinação (IVG), Comprimento de plântulas (CP), Massa Fresca (MF) e Massa Seca (MS) de plântulas e Envelhecimento Acelerado (EA) de sementes de Schizolobium parahyba procedentes dos estados do Rio Grande do Sul, Santa Catarina e Paraná.

Table 2 - Average values of First Count of Germination (PCG), Germination Speed Index (IVG), Seedlings Length (CP), Seedling Fresh Weight (MF), Seedling Dry Weight (MS) and Accelerate Aging Test (EA) of Schizolobium parahyba seeds from Rio Grande do Sul, Santa Catarina and Paraná States.

\begin{tabular}{|c|c|c|c|c|c|c|}
\hline Locais & PCG & IVG & $\mathrm{CP}(\mathrm{cm})$ & MF (g) & MS (g) & EA (\%) \\
\hline $\mathrm{RS}$ & $12 \mathrm{~b} *$ & $0,48 \mathrm{a}$ & $13,40 \mathrm{a}$ & $5,1 \mathrm{a}$ & $0,32 \mathrm{~b}$ & $23 \mathrm{~b}$ \\
\hline $\mathrm{SC}$ & $20 \mathrm{a}$ & $0,66 \mathrm{a}$ & $11,90 \mathrm{a}$ & $4,3 \mathrm{~b}$ & $0,75 \mathrm{a}$ & $35 \mathrm{ab}$ \\
\hline PR & $16 \mathrm{ab}$ & $0,71 \mathrm{a}$ & $12,62 \mathrm{a}$ & $2,6 \mathrm{c}$ & $0,74 \mathrm{a}$ & $42 \mathrm{a}$ \\
\hline $\mathrm{CV}(\%)$ & 2,8 & 37,0 & 11,0 & 7,5 & 8,4 & 3,8 \\
\hline D.M.S & 0,34 & 0,46 & 2,77 & 0,59 & 0,09 & 0,80 \\
\hline
\end{tabular}

* Médias seguidas pela mesma letra, na coluna, não diferem entre si pelo teste de Tukey em nível de 5\% de significância

Tabela 3 - Valores médios de Emergência de plântulas no viveiro (EPV), Sementes Duras no Viveiro (SDV), Sementes Mortas no viveiro (SMV), Altura Média de Mudas (AT), Comprimento de raiz (CR), Diâmetro de Colo (DC), Peso Fresco de mudas (PF) e Peso Seco de mudas (PS) dos testes de avaliação de mudas de Schizolobium parahyba-de sementes procedentes dos estados do Rio Grande do Sul, Santa Catarina e Paraná.

Table 3 - Average values of Seedling Emergence (EPV), Hard Seeds (SDV), Dead Seeds (SMV), Seedlings Height (AT), Root Length $(A R)$, Collar Diameter $(D C)$, Seedlings Fresh Weight $(P F)$ and Seedlings Dry Weight of seedling evaluations tests of Schizolobium parahyba produced from seeds collected in Rio Grande do Sul, Santa Catarina and Paraná states.

\begin{tabular}{ccccccccc}
\hline Locais & EPV $(\%)$ & SDV $(\%)$ & SMV $(\%)$ & AT $(\mathrm{cm})$ & CR $(\mathrm{cm})$ & DC $(\mathrm{cm})$ & PF $(\mathrm{cm})$ & PS $(\mathrm{cm})$ \\
\hline RS & $25 \mathrm{~b} *$ & $65 \mathrm{a}$ & $10 \mathrm{~b}$ & $42 \mathrm{a}$ & $3,0 \mathrm{~b}$ & $4,5 \mathrm{a}$ & $20 \mathrm{~b}$ & $3,3 \mathrm{~b}$ \\
SC & $32 \mathrm{~b}$ & $38 \mathrm{~b}$ & $30 \mathrm{a}$ & $37 \mathrm{~b}$ & $4,0 \mathrm{a}$ & $4,8 \mathrm{a}$ & $28 \mathrm{~b}$ & $4,6 \mathrm{ab}$ \\
PR & $62 \mathrm{a}$ & $28 \mathrm{c}$ & $10 \mathrm{~b}$ & $39 \mathrm{ab}$ & $4,3 \mathrm{a}$ & $4,3 \mathrm{a}$ & $60 \mathrm{a}$ & $10,2 \mathrm{a}$ \\
\hline CV $(\%)$ & 1,7 & 1,6 & 1,5 & 8,6 & 9,6 & 7,4 & 13 & 18,5 \\
D.M.S. & 0,39 & 0,39 & 0,32 & 6,7 & 2,0 & 0,65 & 9,38 & 2,21 \\
\hline
\end{tabular}

Fazendo uma análise nos resultados de avaliação de mudas em viveiro, verifica-se que a procedência PR foi a que apresentou os melhores resultados para 50\% das variáveis observadas. Os resultados de campo são influenciados pelas condições ambientais e climáticas e refletem o comportamento mais próximo daquele que será encontrado na produção de mudas da espécie.

Quando fez-se a correlação entre as variáveis germinação $(\mathrm{G})$ e emergência (EPV) com as avaliações dos demais testes de vigor (Tabela 4), verificou-se correlação significativa e negativa entre a germinação e as sementes mortas em viveiro (RS e PR) e positiva com o peso fresco de mudas (RS, SC e PR).
Com relação à emergência em viveiro (EPV), todas as variáveis, exceto o envelhecimento acelerado em RS e IVG em PR foram, significativamente, correlacionadas demonstrando uma alta relação entre os testes de laboratório e viveiro, como já foi visto em trabalho realizado por Cherobini et al. (2008) com cedro (Cedrela fissilis).

O teste de envelhecimento acelerado, embora tenha se correlacionado significativamente para duas procedências, porém de formas diversas (negativa para SC e positiva para PR), não obteve alta correlação, portanto não pode ser usado seguramente para representação da emergência em viveiro.

Cerne, Lavras, v. 16, n. 3, p. 407-413, jul./set. 2010 
Tabela 4 - Coeficientes de correlação simples (r) entre os dados obtidos nos testes em laboratório e produção de mudas de Schizolobium parahyba em viveiro.

Table 4 - Simple correlation coefficients ( $r$ ) among data got from laboratory tests and from nursery seedling production of Schizolobium parahyba.

\begin{tabular}{cccccccc}
\hline Locais & Variáveis & SMV & PF & IVG & CP & MS & EA \\
\hline \multirow{2}{*}{ RS } & G $(\%)$ & $-0,99 *$ & $0,99 *$ & - & - & - & - \\
& EPV $(\%)$ & - & - & $0,97 *$ & $0,91 *$ & $0,76 *$ & ns \\
\hline \multirow{2}{*}{ SC } & G $(\%)$ & ns & $0,98 *$ & - & - & - & - \\
& EPV $(\%)$ & - & - & $-0,50 *$ & $0,92 *$ & $0,96 *$ & $-0,45 *$ \\
\hline \multirow{2}{*}{ PR } & G $(\%)$ & $-0,68 *$ & $0,29 *$ & 0 & 0 & - & $0,98 *$ \\
& EPV $(\%)$ & - & - & $\mathrm{ns}$ & $0,93 *$ & $0,35 *$ \\
\hline
\end{tabular}

* significativo a 5\% de probabilidade; ns: não-significativo. Em que: G: Germinação; EPV: emergência de plantas no viveiro; SMV: sementes mortas no viveiro; PF : Peso fresco de mudas; IVG: índice de velocidade de germinação; CP: comprimento de plântulas; MS: massa seca de plântulas; EA = envelhecimento acelerado.

\section{CONCLUSÕES}

Em laboratório, as avaliações de primeira contagem de germinação, massa seca e envelhecimento acelerado permitem a diferenciação das procedências em níveis de vigor. Os testes de emergência, comprimento de raiz e peso seco de plântulas permitem a diferenciação das procedências nos testes de viveiro.

A germinação é correlacionada com a variável peso fresco de mudas, e a emergência em viveiro, com o comprimento e massa seca de plântulas, indicando relação entre testes de laboratório e viveiro.

\section{AGRADECIMENTOS}

À Bolsa de Sementes, vinculado ao Programa Verde é Vida, um convênio entre o Departamento de Ciências Florestais da UFSM e a Associação de Fumicultores do Brasil (AFUBRA) que forneceu as sementes para a realização deste trabalho.

\section{REFERÊNCIAS BIBLIOGRÁFICAS}

BRASIL. Ministério da Agricultura e Reforma Agrária. Regras para análise de sementes. Brasília, 1992. 365 p.

CHEROBINI, E. A. I.; MUNIZ, M. F. B.; BLUME, E. Avaliação da qualidade de sementes e mudas de cedro. Ciência Florestal, Santa Maria, v. 18, n. 1, jan./mar. 2008.

FERREIRA, F. A. Patologia florestal: principais doenças florestais no Brasil. Viçosa, MG: UFV, 1989. 570 p.
KRYZANOWSKI, F. C.; VIEIRA, R. D.; FRANÇA NETO, J. B. Vigor de sementes: conceitos e testes. Londrina: ABRATES, 1999. p. 8.1-8.28.

LORENZI, H. Árvores brasileiras: manual de identificação e cultivo de plantas arbóreas no Brasil. 4. ed. Nova Odessa: Instituto Plantarum, 2002. v. 1.

MACHADO, C. F.; OLIVEIRA, J. A. de; DAVIDE, A. C.; GUIMARÃES, R. M. Metodologia para a condução do teste de germinação em Ipê-amarelo. Cerne, Lavras, v. 8, n. 2, p. 17-25, 2002.

MARCOS FILHO, J. Teste de envelhecimento acelerado. In: VIEIRA, R. D.; CARVALHO, N. M. (Eds.). Teste de vigor em sementes. Jaboticabal: FUNEP, 1994. p. 133-149, 164 p.

MEDEIROS, A. C. S. Armazenamento de sementes de espécies florestais nativas. Colombo: Embrapa Florestas, 2001. 24 p. (Documentos, 66).

NAKAGAWA, J. Testes de vigor baseados no desempenho de plântulas. In: KRZYZANOWSKI, F. C.; VIEIRA, R. D.; FRANÇA NETO, J. B. (Eds.). Vigor de sementes: conceitos e testes. Londrina: ABRATES, 1999.

NEEGAARD, P. Seed pathology. London: MacMillan, 1979. v. 1,829 p.

Cerne, Lavras, v. 16, n. 3, p. 407-413, jul./set. 2010 
PEREZ, S. C. J. G. A.; FANTI, S. C.; CASALI, C. A. Influência do armazenamento, substrato, envelhecimento precoce e profundidade de semeadura na germinação de canafístula. Bragantia, Campinas, v. 58, n. 1, p. 57-68, 1999.

POPINIGIS, F. Fisiologia da semente. Brasília: Ministério da Agricultura; AGIPLAN, 1985. 289 p.

SCALON, S. P. Q. et al. Potencial germinativo de sementes de Dimorphandra mollis Benth. em armazenamento, tratamentos pré-germinativos e temperatura de incubação. Cerne, Lavras, v. 13, n. 3, p. 321-328, jul./set. 2007.
SILVA, M. A. S.; TORRES, S. B.; CARVALHO, I. M. S. Teste de envelhecimento acelerado em sementes de maxixe (Cucumis anguria L.). Revista Brasileira de Sementes, Brasília, v. 25, n. 2, p. 48-52, 1998.

SOUZA CRUZ. Reflorestar é preservar. Florianópolis, 2001. $47 \mathrm{p}$.

ZONTA, E. P.; MACHADO, A. A. Sistema de análise estatística para microcomputadores - SANEST. Pelotas: UFPel, 1986. $150 \mathrm{p}$. 